\title{
Practicality of Coordinate Indexing
}

$M r$. Randall is $A E D C$ librarian, $A R O$, Inc., Tullahoma, Tenn.

Coordinate indexing obtained its first large scale audience in February 1953 when the ASTIA report catalog cards listing the Uniterms on the back were distributed. The basic principles of coordinate indexing are relatively simple. The system of using subject headings, as practiced by librarians and commercial indexers, is discarded. Instead, the subject content of the item to be indexed is broken down into its major concepts, and single words, called Uniterms, are selected by the indexer to denote the concepts. As many Uniterms are used as are necessary to index any single item. In the first 45 ASTIA cards reviewed, the number of Uniterms used ranged from four to twelve and averaged eight per report. Each item to be indexed by the system is assigned an accession number and each Uniterm used is recorded on a card. As a report is indexed, its accession number is recorded on the appropriate Uniterm cards. The searcher selects the Uniterms which describe the information for which he is looking and compares the Uniterm cards for common accession numbers. The reports having the common accession numbers contain, according to the proponents of the system, the information desired.

The advocates of coordinate indexing claim many advantages for the system including a reduction in the elephantine size of the card catalog, a technique which permits the user to locate easily the specific information desired, and a decrease in the librarian's work load.
A small report collection of 20,000 reports may be indexed conventionally by approximately I IO,000 cards as follows: 20,000 report number cards, 50,000 personal and corporate author cards, and 40,000 subject cards. It is conceivable that coordinate indexing techniques might be applied to the author file but to do so would provoke as many problems as it would solve. The card catalog utilizing the coordinate indexing system would probably include the following: 20,000 accession cards, 20,000 report number cards, 50,000 personal and corporate author cards and 8,000 or more Uniterm cards, a total of 98,000 cards which represents a reduction of slightly over $10 \%$. A careful count and study might justify a slightly larger reduction but the savings in size would remain in the $10 \%$ category and would not approach that implied by the use of a single Uniterm card to replace two hundred subject cards.

Coordinate indexing does permit a searcher to limit the subject area of the search by increasing the number of Uniterms he combines in his search for common accession numbers. By comparing five or six Uniterm cards, the user could establish that "report I8,735" covers the "metallurgical analysis of high carbon steel bearings." Unfortunately, the searcher who is interested only in the subject of steel metallurgy would also be referred to the same report. Uniterms permit a fineness of subject searching usually impossible under the normal subject heading approach; however, the system may prove more of a hindrance than a help to one in quest of general information.

One major disadvantage inherent in the 
system is the frequency with which Uniterms used to index a report may be combined to indicate a subject content not warranted by the information appearing in the report. Even in reports on a fairly limited subject it was found, in the inspection of the first 45 ASTIA Uniterm cards received, that an average of nearly one false lead per report could be constructed. A report on a subject such as "Friction wear of steel bearings in a bronze housing" would be indexed with such Uniterms as: Steel, Bearings, Friction, and Bronze. A searcher interested in bronze bearings would be referred to this report. The experienced library user expects only a few references, perhaps only one, to contain the exact information he desires; but he has a right to expect that the references he is given will contain the information indicated by the subject headings he used. If, however, he finds only information on steel bearings when the system promising selectivity indicates he may expect information on bronze bearings, he may be excused for losing faith in the catalog. A very effective campaign to create good-will among library users may be completely destroyed by such reactions as this to the library's primary tool.

The process of locating information in a coordinate-indexed file is usually depicted as comparing a single card for each of two or three Uniterms for common accession numbers. In a large specialized collection it may not be nearly as simple as that. In an aeronautical library of less than 25,000 reports there are over 1,500 subject cards filed behind "Wings"; there are nearly as many cards which would require listing on the Uniterm card "Supersonic." It would require a large table just to lay out all of the Uniterm cards necessary to find information on the effect of wing flutter on the longitudinal stability of supersonic aircraft. With at least eight different Uni- term cards for "wings" and eight for "supersonic," plus one each for "flutter" and for "stability," the search would require that the user have persistence, patience and strong eyes. The end result of the comparison would be merely a list of numbers; there is no opportunity for making a preliminary scanning and selection, as is possible in the common subject heading catalog.

It might be well to look at coordinate indexing from the librarian's point of view as well as from that of the user. One of the big criticisms of the various document cataloging systems has been the time cost in establishing and maintaining a card catalog for use. Will the system of coordinate indexing diminish this burden on the librarians? Unfortunately, no. The review of the first several batches of the Unitermindexed ASTIA cards indicated that approximately four times as many Uniterms as subject headings were used for indexing the covered reports. The first batch of 45 reports required 88 subject headings and 355 Uniterms.

Subject heading cards can be processed for filing and filed at a rate of 60 cards or more per hour. These cards lend themselves to processing by mass production techniques. Each subject card in a set can be appropriately checked or underscored as a guide for filing. As the cards are marked they can be sorted into four or six piles for ease in subsequent alphabetizing. After the cards are completely arranged they are interfiled in the subject file. At the rate mentioned above, the 88 cards for the 45 reports could be processed and filed in an hour and a half.

Uniterm cards cannot be processed as easily or as quickly. The Uniterm cards for any one report must be first pulled from the catalog. Instead of simple checking or underscoring, the accession number for the 
report indexed must be typed or carefully written in the appropriate column. The Uniterm cards are then refiled in the catalog. The system does not lend itself to mass production techniques and only the Uniterm cards for any one report should be pulled at a time. This requires the puller to work the entire subject catalog from $A$ to $Z$ for each report. The employee who can process a set of standard subject heading cards at 60 cards per hour would, indeed, be fortunate to handle 45 Uniterm cards for any one report should cessing the Uniterm cards for the 45 reports would require nearly eight hours as compared to the ninety minutes required for the subject heading cards for the same reports.
Although it is too early to evaluate properly the system of coordinate indexing after the limited review made possible by the receipt of the first few batches of the ASTIA Uniterm cards, the review does indicate that it is probably too early for the originators to release the system to the public. Some device or technique must be evolved which will make impossible the combination of Uniterms which provide false leads. Also necessary will be some device to minimize the posting time which now requires approximately five times as much time as the processing of standard subject heading cards. The same device might conceivably be utilized for rapid and exact scanning of Uniterm cards for common accession numbers.

\section{Comments on "Practicality of Coordinate Indexing".}

Documentation, Incorporated is grateful to the editor of COLLEGE AND RESEARCH LIBRARIES for the opportunity to comment on Mr. Randall's article, "Practicality of Coordinate Indexing." We have prepared our answer as a series of points rather than as a continuous discussion.

I) Mr. Randall fails to distinguish between coordinate indexing as a general method and the Uniterm System as a particular manual application of coordinate indexing.

2) Mr. Randall's description of coordinate indexing is not full or complete. We can refer those interested to the numerous published papers on the Uniterm System.

3) The Uniterm System as a system of subject control is comparable in size to a standard subject heading system. Mr. Randall's comparison of the Uniterm System to a full system involving author cards, corporate entry cards, etc., is just not to the point. We have, however, recently prepared a Uniterm index in which corporate authors are treated as Uniterms for direct coordination with subjects. Whether a standard system needs an accession number file depends on extrane- ous factors, e.g., how material is cited and what other bibliographical tools are available.

4) We have always recognized the theoretical problem of false coordination and have published an account of one method of avoiding it. However, our own studies have indicated that, as a matter of fact, false coordination does not occur often enough to constitute a serious problem. If it did, not only the Uniterm System, but all mechanized systems of "coordinating" information would suffer thereby. It is too bad that Mr. Randall does not give the examples which he found on the ASTIA Uniterm cards. It is curious that having found so many examples of false coordination, he gives no reference to them, but instead constructs a hypothetical example. At least, without a reference, we have not been able to find a card indexed by the Uniterms in his example.

5) Mr. Randall assumes that a Uniterm card only holds 200 numbers. The cards normally used $\left(5^{\prime \prime} \times 8^{\prime \prime}\right)$ contain positions for 500 numbers.

6) In the example of a laborious search which Mr. Randall uses, namely a search for information on "the effect of wing flutter on the longitudinal stability of supersonic air- 
craft," he omits the fact that there would be a Uniterm card for longitudinal. He also overlooks the statement which we have made over and over again, to the effect that coordination is always carried out between two terms, and that the results of the first coordination are then carried over to a coordination with a third term, etc. The attempt to coordinate four terms at once indicates a lack of familiarity with the theory and practice of narrowing a search.

7) We have always recognized the burden of posting and have continued research on this subject. We have been able so far to describe partially ten different methods of posting. The best of these methods makes it possible to post a Uniterm index two or three times as rapidly as filing in a standard catalog, and we mean here total time and not unit time. We have published reports which indicate that Uniterm indexing reduces the time required for subject analysis of material from 200 to $300 \%$. Our methods of posting also reduce catalog maintenance by the same dramatic percentage.

8) $\mathrm{On}$ the matter of whether it is too early to release the system, we can only say that this is a decision made by the agencies for whom we work. Mr. Randall has based his judgment on 45 cards. We have already indexed over 20,000 documents using the Uniterm System. We have also published two Uniterm indexes in book form. It would seem that judgment on the Uniterm System or its practicality should be based on an example of more than 45 cards-Mortimer Taube, Documentation, Inc., Washington, D.C.

\section{Financial Problems of: University Libraries}

\section{(Continued from page 410)}

non-professional, at a cost of $\$ 814,368$. California (Berkeley) has $297 \frac{1}{2}$, of whom I 24 are professional and $173 \frac{1}{2}$ non-professional with a budget for salaries of $\$ \mathrm{I}, 079,386$.

The following tabulation lists some of the university libraries currently operating with approximately the staff relationship proposed in the preceding paragraph.

Such operations should provide a better distribution of duties, a more efficient operation, and greater economy. It may offer one way of getting more out of the salaries budget without lowering the percentage used for books, periodicals and binding.

In summary, it may be said that any approach to the financial problems of the university library should be made without apology for present demands on the university budget, since 1950 figures indicate only one-half of one per cent change from 1930.

The methods considered in this approach
TABLE II

\begin{tabular}{|c|c|c|c|}
\hline & Prof. & Non-Prof. & Total \\
\hline Brown & 22 & 36 & $5^{8}$ \\
\hline Cincinnati & 16 & 29 & 45 \\
\hline Columbia & 95 & 225 & 320 \\
\hline Fordham & 13 & $2 \mathrm{I}$ & 34 \\
\hline Iowa & $3 \circ \frac{1}{4}$ & 47 & $77^{\frac{1}{4}}$ \\
\hline Iowa State & 19 & 27 & 46 \\
\hline Massachusetts & 4 & 9 & I3 \\
\hline Miami & 19 & $34 \frac{1}{2}$ & $53 \frac{1}{2}$ \\
\hline Missouri & 26 & $36^{2}$ & 62 \\
\hline New York & 43 & II 6 & I 59 \\
\hline Pennsylvania & $55 \frac{1}{2}$ & $98 \frac{3}{4}$ & I $54 \frac{1}{4}$ \\
\hline Princeton & $47 \frac{3}{4}$ & 67 & I I $4 \frac{3}{4}$ \\
\hline Purdue & 23 & 30 & \\
\hline South Carolina & I $2 \frac{5}{6}$ & 21 & $33^{5}$ \\
\hline St. Louis & 15 & 20 & 35 \\
\hline Tennessee & 22 & 36 & 58 \\
\hline Utah & $20 \frac{2}{3}$ & 30 & $50 \frac{2}{3}$ \\
\hline Virginia & 29 & $39 \frac{1}{2}$ & $68 \frac{1}{2}$ \\
\hline Wayne & 22 & $38 \frac{1}{8}$ & $60 \frac{1}{8}$ \\
\hline
\end{tabular}

to the problem include the possibility of greater cooperation in acquisition and use of materials, the possibility of more funds from specific research contracts, and the possibility of more efficient use of staff. 